\title{
Asymptomatic unilateral pulsatile eye: Clinical and therapeutic evaluation of sphenoid bone defect in neurofibromatosis type I
}

\author{
Ka Lung Chong, Syeb Shoeb Ahmad, Fatimah Hussin, \\ Norlina Mohd Ramli, Shuaibah Abdul Ghani
}

\begin{abstract}
Introduction: Neurofibromatosis type I (NF-1) is a common inherited, multisystem, neurocutaneous disorder that predisposes to the development of benign and malignant tumors. Orbital-temporal manifestations of neurofibromatosis are not common. Case Report: We report a rare case of atypical presentation of NF-1 which presented to us with incidental asymptomatic unilateral pulsatile eye. After investigation, the patient was found to have unilateral partial sphenoid bone defect. No other orbital-temporal manifestation of neurofibromatosis was noted. Conclusion: The pathogenesis of unilateral greater wing defect in NF-1 is still unclear. Some authors have reported that the sphenoid bone defect may progress. If the defect does progress, we need to follow-up to monitor sphenoid bone defect manifestation in every orbital-temporal NF-1 patient.
\end{abstract}

Keywords: Sphenoid bone defect, Orbitaltemporal neurofibromatosis, Greater wing defect, Pulsatile eye, Neurofibromatosis type I (NF-1)

Ka Lung Chong ${ }^{1}$, Syeb Shoeb Ahmad ${ }^{1}$, Fatimah Hussin ${ }^{2}$, Norlina Mohd Ramli ${ }^{3}$, Shuaibah Abdul Ghani ${ }^{1}$

Affiliations: ${ }^{1}$ Department of Ophthalmology, Queen Elizabeth Hospital, Kota Kinabalu, Sabah, Malaysia; 'Department of Radiology, Queen Elizabeth Hospital, Kota Kinabalu, Sabah, Malaysia; ${ }^{3}$ Department of Ophthalmology, University of Malaya Medical Centre, Malaysia.

Corresponding Author: Ka Lung Chong, Department of Ophthalmology, Queen Elizabeth Hospital, Kota Kinabalu, 88586 Sabah, MALAYSIA ;Tel: +6088218684; Fax: +6088252827; Email: pbdckl@hotmail.com

Received: 25 April 2013

Accepted: 21 June 2013

Published: 01 November 2013
Chong KL, Ahmad SS, Fatimah H, Ramli NM, Ghani SA. Asymptomatic unilateral pulsatile eye: Clinical and therapeutic evaluation of sphenoid bone defect in neurofibromatosis type I. International Journal of Case Reports and Images 2013;(11):623-626.

$$
* * * * * * * * *
$$

doi:10.5348/ijcri-2013-11-395-CR-9

\section{INTRODUCTION}

Asymptomatic unilateral pulsatile eye due to greater wing defect of sphenoid bone is rarely the first sign of neurofibromatosis type I (NF-1). We report a rare case of orbital-temporal NF-1 which was found to have only unilateral partial sphenoid bone defect.

\section{CASE REPORT}

A 26-year-old young male was admitted to intensive care unit (ICU) in Queen Elizabeth Hospital, Kota Kinabalu, Sabah, Malaysia for severe pneumonia. He was referred to our ophthalmology team after an incidental observation of a pulsatile movement of this left eye. The patient did not have ocular or visual complains and history of ocular or head trauma. Past medical or surgical histories were not significant. There was no similar condition in the family.

On ophthalmology examination his visual acuity was $6 / 6$ in both eyes. Both eyes were symmetrical in position. There was neither proptosis nor enophthalmos (Hertel exophthalmometry measured $18 \mathrm{~mm}$ and $17 \mathrm{~mm}$ at 103 base reading). The left eye was pulsatile and the pulsatile were synchronous with the carotid pulse (Video 1). No thrill or bruit was detected over the eyeball, forehead or neck. Intraocular pressures (IOP) were $17 \mathrm{mmHg}$ 
and $18 \mathrm{mmHg}$ in the right and left eyes, respectively. There were no Lisch nodules in either eye. Fundoscopy was normal in both eyes. Physical examination revealed thoracic scoliosis, axillaries freckling and multiple Caféau-lait spots on his trunk with majority measuring more than $3 \mathrm{~cm}$ in size. The rest of the physical examination was unremarkable.

Computed tomography (CT) scans of brain and orbits demonstrated partial defect of the left greater sphenoid wing (Figures 1 and 2). Three-dimensional images were constructed and showed details of a bony defect in the left orbit. A diagnosis of NF-1 was made. Magnetic resonance imaging (MRI) scan of brain was done later which showed diffuse intrinsic pontine glioma in the brainstem (Figure $3 \mathrm{~A}-\mathrm{C})$. The patient passed away two months later due to complication of recurrent aspiration pneumonia.

Video 1: Pulsatile left eye.

Video URL: http://192.168.1.60:4444/ijcasereportsandimages. com/archive/2013/o11-2013-ijcri/oo9-11-2013-chong/ijcrio0911201399-chong-full-text.php

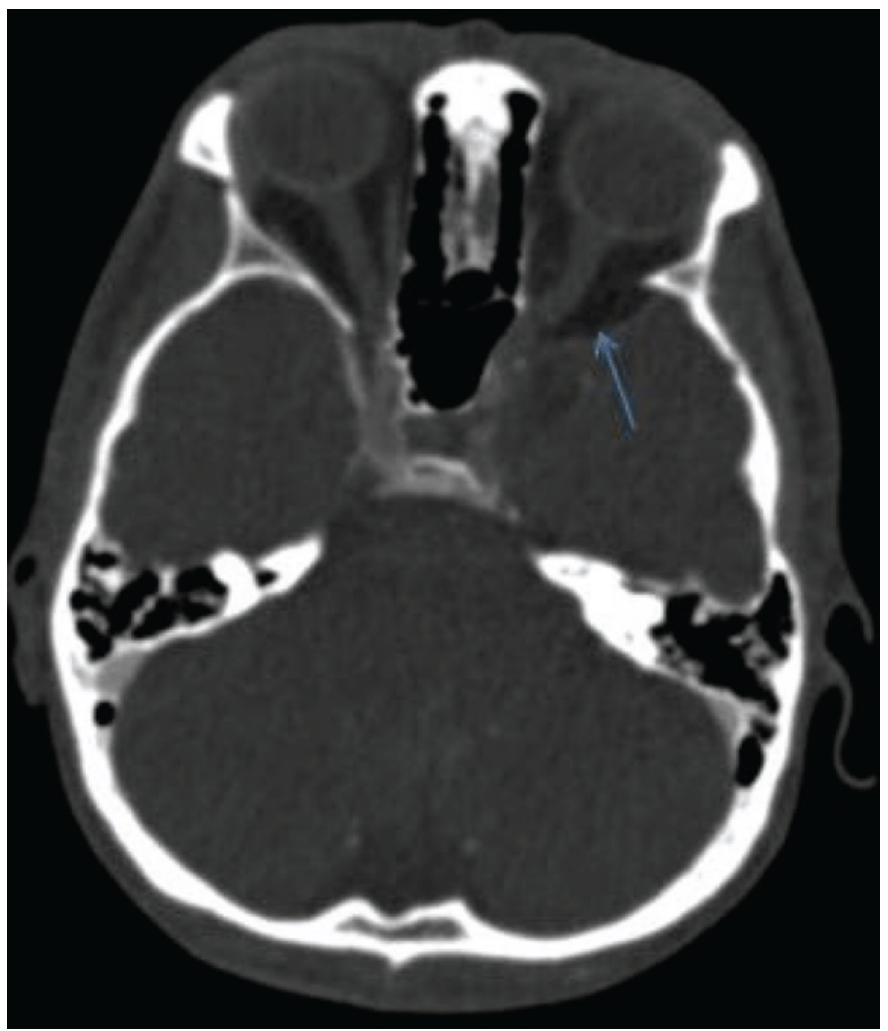

Figure 1: Computed tomography orbits in bone setting showing a large bony defect affecting the left sphenoid wing $(\leftarrow)$.

\section{DISCUSSION}

Neurofibromatosis type I, formerly known as von Recklinghausen disease, which was named after the researcher who first documented the disorder (Friedrich Daniel von Recklinghausen), is the most common

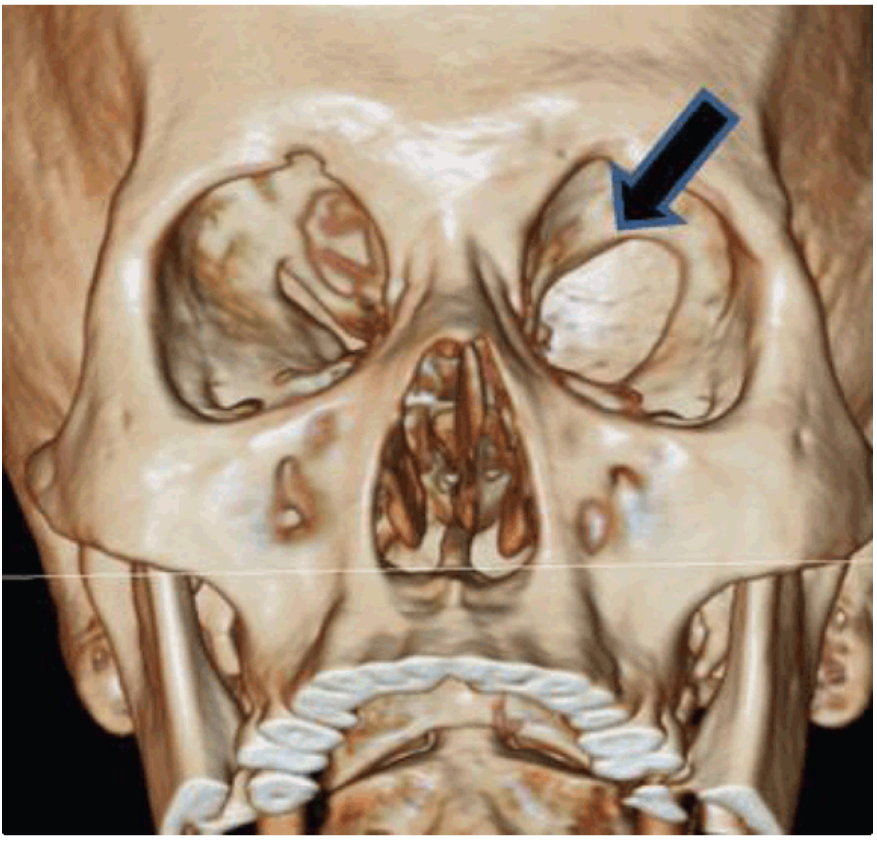

Figure 2: 3D reconstruction of the facial bones showing a large bony defect in the left posterior orbit.
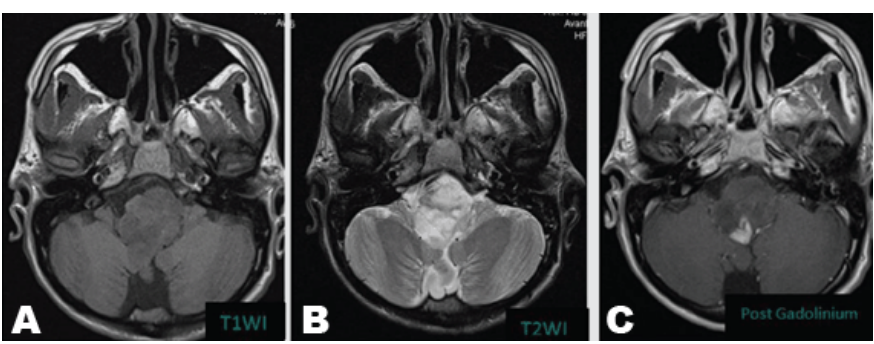

Figure 3: Magnetic resonance imaging (MRI) brain showing an ill defined potine mass which is predominantly isointense to grey matter on T1WI and hyperintense on T2WI with heretogeneous enhancement in post gadolinium with cystic component. This may represent intrinsic pontine glioma commonly found in neurofibromatosis type 1.

inherited disorder caused by a mutation of a gene on the long arm of chromosome 17 [1] . Neurofibromatosis type I gene encodes a protein known as neurofibromin which acts as a tumor suppressor protein. It is an autosomal dominant genetic disorder but up to $50 \%$ of NF-1 cases arise due to spontaneous mutation. The incidence of NF-1 is about 1 in 3500 live births [2].

Orbital-temporal manifestations of NF-1 have been found to exist in $1-10 \%$ of patients and are characterized by pulsatile exophthalmos, pulsatile enophthalmos, orbital neurofibroma, sphenoid wing dysplasia, expansion of the temporal fossa and herniation of the temporal lobe into the orbit [3]. It can be classified into three groups (group 1: orbital soft-tissue involvement only with a seeing eye, group 2: orbital soft-tissue and significant bone involvement with a seeing eye, and group 3: orbital soft-tissue and significant bone involvement with a blind or absent eye) [4]. Our patient belonged to group 2 and 
only had a dysplasia of the greater wing of the sphenoid bone. Besides that, he did not have other orbital-temporal manifestations or ocular symptoms which were very different from other reported cases in literature [5].

Unilateral pulsatile eye can be caused by a vascular lesion in the orbit (e.g., orbital varices), carotid-cavernous fistula or defect of the sphenoid bone in the orbit. Greater wing defect of sphenoid bone can be present with clinical features such as pulsatile eye movement, headache, proptosis and diplopia with consecutive herniation of the temporal lobe. Our patient did not have any ocular symptoms except the incidental finding of a pulsatile eye.

Sphenoid dysplasia occurs in less than $1 \%$ of NF-1 patients. Further, abnormalities of the sphenoid wings are often considered pathognomonic [6]. According to National Institute of Health (NIH), abnormalities of the sphenoid wings are one of the diagnostic criteria for NF-1 (Table 1). Usually, this manifestation occurs unilaterally. There are still many controversies regarding the origin of this sphenoid bone dysplasia in neurofibromatosis. Although it has been regarded as a developmental anomaly of mesodermal origin, the exact mechanism for the sphenoid bone changes seen in neurofibromatosis is uncertain. An abnormality in the skull and orbital development, altered transmission of cerebrospinal fluid pulsations and interaction between plexiform neurofibroma and sphenoid bone are postulated as possible mechanisms [7]. In our case, there was no plexiform neurofibroma in the brain but the sphenoid bone defect was present. Review of literature has revealed this greater wing defect is not congenital. It may progress and eventually become typical sphenoid bone dysplasia [6].

When the greater wing defect is sufficient to allow the temporal lobe to herniate into the orbital cavity it may appear as an exophthalmos and gross facial deformity.

Table 1: Diagnostic criteria for neurofibromatosis type 1. At least two major criteria are required.

- A distinctive osseous lesion such as sphenoid dysplasia or thinning of long bone cortex, with or without pseudoarthrosis

- Two or more Lisch nodules (iris hamartomas)

- Optic glioma

- Axillary or inguinal freckling

- Six or more café-au-lait spots, $>0.5 \mathrm{~cm}$ in prepubertal children; $>1.5 \mathrm{~cm}$ in postpubertal individuals

- Two or more cutaneous neurofibromas

- One plexiform neurofibroma

- A first degree relative (parent, sibling, or offspring) with NF- 1 by the above criteria

Abbreviation: Neurofibromatosis type I (NF-1)
Conversely, the orbital fat may prolapse into the middle cranial fossa and cause enophthalmos.

The greater wing defect is corrected for both cosmetic and functional reasons. Surgical correction can be performed through an intracranial approach or lateral orbital approach but the former method is associated with a high complication rate. Traditional surgical treatment of sphenoid dysplasia involves split bone grafting and repair of the anterior skull base defect. However, the results of this procedure may not be entirely sustainable owing to bone graft resorption and recurrence of proptosis and pulsating exophthalmos. A newer method utilities- a titanium mesh in conjunction with bone graft to act as a barrier between the orbit and the middle cranial fossa [8].

\section{CONCLUSION}

Sphenoid bone dysplasia is one of the diagnostic criteria for neurofibromatosis type I. However, it is very rare for neurofibromatosis type I patient, which first presented with pulsatile eye movement. In our patient, his pulsatile eye was noted incidentally and did not have any ocular or visual symptom despite he had greater wing defect of sphenoid bone. The pathogenesis of unilateral greater wing defect in neurofibromatosis type I was not clear. Some literatures reported that the sphenoid bone defect may progress. We need to follow-up to monitor the defect manifestation in every orbital-temporal neurofibromatosis type I patient.

\section{Author Contributions}

Ka Lung Chong - Substantial contributions to conception and design, Drafting the article, Revising it critically for important intellectual content, Final approval of the version to be published

Syeb Shoeb Ahmad - Substantial contributions to conception and design, Drafting the article, Revising it critically for important intellectual content, Final approval of the version to be published

Fatimah Hussin - Substantial contributions to conception and design, Drafting the article, Revising it critically for important intellectual content, Final approval of the version to be published.

Norlina Mohd Ramli - Substantial contributions to conception and design, Drafting the article, Revising it critically for important intellectual content, Final approval of the version to be published.

Shuaibah Abdul Ghani - Substantial contributions to conception and design, Drafting the article, Revising it critically for important intellectual content, Final approval of the version to be published.

\section{Guarantor}

The corresponding author is the guarantor of submission. 


\section{Conflict of Interest}

Authors declare no conflict of interest.

\section{Copyright}

(C) Ka Lung Chong et al. 2013; This article is distributed under the terms of Creative Commons attribution 3.0 License which permits unrestricted use, distribution and reproduction in any means provided the original authors and original publisher are properly credited. (Please see www.ijcasereportsandimages.com/copyright-policy.php for more information.)

\section{REFERENCES}

1. Skuse GR, Kosciolek BA, Rowley PT. The neurofibroma in von Recklinghausen neurofibromatosis has a unicellular origin. Am J Hum Genet 1991 Sep;49(3):600-7.

2. Rasmussen SA, Friedman JM. NF1 gene and neurofibromatosis 1. Am J Epidemiol 2000 Jan 1;151(1):33-40.
3. Havlik RJ, Boaz J. Cranio-orbital-temporal neurofibromatosis: are we treating the whole problem? J Craniofac Surg 1998 Nov;9(6):529-35.

4. Jackson IT, Carbonnel A, Potparic Z, Shaw K. Orbitotemporal neurofibromatosis: classification and treatment. Plast Reconstr Surg 1993 Jul;92(1):1-11.

5. Harkens K, Dolan KD. Correlative imaging of sphenoid dysplasia accompanying neurofibromatosis. Ann Otol Rhinol Laryngol 1990 Feb;99(2 Pt 1):137-41.

6. Macfarlane $\mathrm{R}$, Levin AV, Weksberg $\mathrm{R}$, Blaser $\mathrm{S}$, Rutka JT. Absence of the greater sphenoid wing in neurofibromatosis type I: congenital or acquired: case report. Neurosurgery $1995 \mathrm{Jul} ; 37(1): 129-33$.

7. Jacquemin C, Bosley TM, Liu D, Svedberg H, Buhaliqa A. Reassessment of sphenoid dysplasia associated with neurofibromatosis type 1 . AJNR Am J Neuroradiol 2002 Apr;23(4):644-8.

8. Lotfy M, Xu R, McGirt M, Sakr S, Ayoub B, Bydon A, Reconstruction of skull base defects in sphenoid wing dysplasia associated with neurofibromatosis I with titanium mesh. Clin Neurol Neurosurg 2010 Dec;112(10):909-14.
Access full text article on other devices

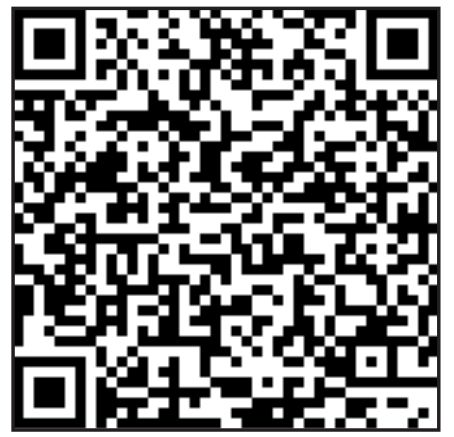

Access PDF of article on other devices

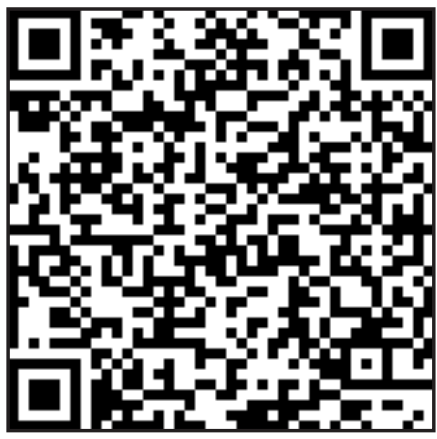

